\title{
EVN GENCO 2 - VĂN HÓA DOANH NGHIỆP LÀ Gì?
}

\author{
EVN GENCO 2 CTCP Nhiệt Điện Hải Phòng
}

December 26, 2016

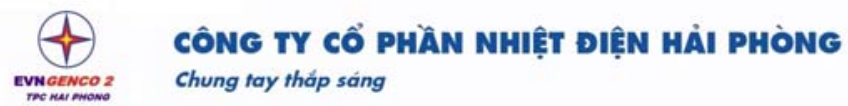

http://www.ndhp.com.vn/newsg/5/7495/VAN-HOA-DOANH-NGHIEP-LA-

GI/default.aspx 


\section{CÔNG TY CỔ PHẦN NHIỆT DIỆN HẢI PHÒNG Chung tay thắp sáng}

(/Default.aspx)

A (/Default.aspx) GIÓ'I THIẸU (/FULLNEWSG/1/GIOI-THIEU/DEFAULT.ASPX)

QUAN HẸ CỎ ĐÔNG $\vee$ (http://ndhp.com.vn/newsg/12/9636/Quan-He-Co-Dong/default.aspx)

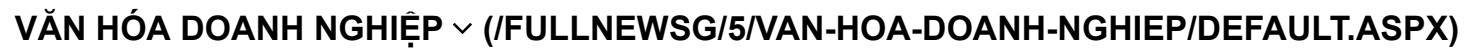

ĐẢNG ỦY ĐOÀN THẺ $\vee$ (/FULLNEWSG/10/DANG-UY-DOAN-THE/DEFAULT.ASPX)

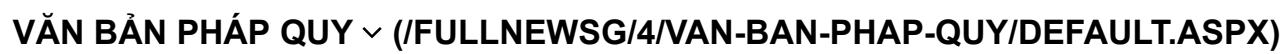

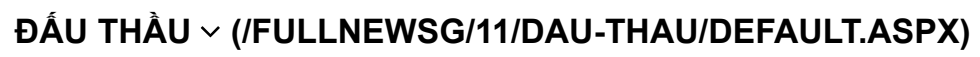

\section{A TRANG CHỦ (/Default.aspx) > VĂN HÓA DOANH NGHIẸP (/fullnewsg/5/VAN-HOA-DOANH- NGHIEP/default.aspx) > TIN VĂN HÓA (/Category/5/285/TIN-VAN-HOA/default.aspx) \\ VĂN HÓA DOANH NGHIẸP LÀ Gì?}

Ngày cập nhật: 25/12/2016

Văn hoá doanh nghiệp là một yêu cầu tất yếu của sự triển thương hiệu vì hình ảnh văn hóa doanh nghiệp sẽ góp phần quảng bá thương hiệu của doanh nghiệp. Văn hoá doanh nghiệp chính là tài sản vô hình của mỗi doanh nghiệp.

Khái niệm văn hóa doanh nghiệp

Yếu tố văn hoá luôn hình thành song song với quá trình phát triển của doanh nghiệp. Văn hoá doanh nghiệp là văn hoá của một tổ chức vì vậy nó không đơn thuần là văn hoá giao tiếp hay văn hoá kinh doanh, nó cũng không phải là những khẩu hiệu của ban lãnh đạo được treo trước cổng hay trong phòng họp. Mà nó bao gồm sự tổng hợp của các yếu tố trên. Nó là giá trị, niềm tin, chuẩn mực được thể hiện trong thực tế và trong các hành vi mỗi thành viên doanh nghiệp.

Văn hóa doanh nghiệp là gì?

Có rất nhiều định nghĩa xung quanh khái niệm này. Mỗi nền văn hóa khác nhau có các định nghĩa khác nhau. Mỗi doanh nghiệp lại có một cách nhìn khác nhau về văn hóa doanh nghiệp. Hiện có trên 300 định nghĩa khác nhau về văn hoá doanh nghiệp. Có một vài cách định nghĩa văn hoá doanh nghiệp như sau:

"Phẩm chất riêng biệt của tổ chức được nhận thức phân biệt nó với các tổ chức khác trong lĩnh vực". (Gold, K.A.) 
"Văn hóa thể hiện tổng hợp các giá trị và cách hành xử phụ thuộc lẫn nhau phổ biến trong doanh nghiệp và có xu hướng tự lưu truyền, thường trong thời gian dài”. (Kotter, J.P. \& Heskett, J.L.)

"Văn hóa doanh nghiệp là những niềm tin, thái độ và giá trị tồn tại phổ biến và tương đối ổn định trong doanh nghiệp". (Williams, A., Dobson, P. \& Walters, M.)

Còn nếu nói nôm na: Nếu doanh nghiệp là máy tính thì văn hóa doanh nghiệp là hệ điều hành. Nói một cách hình tượng thì: Văn hóa là cái còn thiếu khi ta có tất cả, là cái còn lại khi tất cả đã mất.

Tuy nhiên, mọi định nghĩa đều có nét chung coi văn hoá doanh nghiệp là toàn bộ các giá trị văn hóa được xây dựng trong suốt quá trình tồn tại và phát triển của doanh nghiệp, chi phối tình cảm, nếp suy nghĩ và hành vi của mọi thành viên của doanh nghiệp; tạo nên sự khác biệt giữa các doanh nghiệp và được coi là truyền thống riêng của mỗi doanh nghiệp.

\section{Văn hóa doanh nghiệp, bắt nguồn từ những giá trị}

Cốt lõi của văn hoá doanh nghiệp là tinh thần doanh nghiệp và quan điểm giá trị của doanh nghiệp. Trong cuốn sách Văn mình làm giàu và nguồn gốc của cải của TS. Vương Quân Hoàng, chúng ta đã được đề cập tới khái niệm giá trị. Giải thích một cách đơn giản, giá trị là một cái gì đó mà người ta cảm thấy quan trọng, có ích. Cụm từ "Quan trọng" và "Có ích lợi" là rất đáng lưu tâm trong xây dựng văn hóa doanh nghiệp. Bởi lẽ lãnh đạo công ty sẽ rất khó xây dựng văn hóa doanh nghiệp, nếu không bảo vệ ích lợi mà văn hóa doanh nghiệp đem lại. Nhân viên cần được giáo dục nhận thức rằng việc đeo thẻ nhân viên, mặc đồng phục là thể hiện sự tự hào là thành viên của công ty, và có ích cho công việc của họ chứ không phải họ mang những thứ đó để làm quảng cáo.

Rất nhiều lãnh đạo đã mắc lỗi khi áp đặt văn hóa mà không khơi gợi nhận thức của nhân viên mình với các giá trị văn hóa. Nếu không giảng giải được cặn kẽ hệ thống các giá trị văn hóa của doanh nghiệp có ích lợi gì với nội bộ tổ chức, tất yếu mọi hình thức triển khai chỉ là phong trào. Một câu hỏi được đặt ra rằng, vậy những giá trị nào là hợp lý và giá trị nào là không hợp lý. Điều này tùy thuộc rất nhiều vào từng tổ chức riêng biệt, nhưng tựu chung lại, có một số giá trị được đề cao trong nội bộ tổ chức ở Việt Nam đó là:

- Sự thành thực (thể hiện là nói thật, không gian dối, cam kết thực hiện những gì mình hứa hẹn và đảm bảo đúng những gì mình sẽ thực hiện)

- Sự tự giác (thể hiện ở mức độ sẵn sàng với công việc, không ngại khó khăn, làm việc hết mình vì lợi ích của tổ chức)

- Sự khôn khéo (biết nói những gì cần nói, hỏi những điều cần hỏi, tranh luận những điều đáng tranh 
luận và sắp xếp những gì hợp lý nhất)

Ngoài ra còn một số giá trị khác được đề cập tới như sự tự tin, sáng tạo ... Những giá trị này sẽ là nền tảng định hướng cho văn hóa của doanh nghiệp.

\section{Các tin khác}

4 Một số hoạt động an sinh xã hội nhân dịp kỷ niệm 73 năm ngày Thương binh liệt sỹ (27/7/1947 27/7/2020) (../../9810/Mot-so-hoat-dong-an-sinh-xa-hoi-nhan-dip-ky-niem-73-nam-ngay-Thuong-binh-lietsy-2771947-2772020/default.aspx) (29/07/2020)

4 Có một người kỹ sư đa tài như thế (../../9791/Co-mot-nguoi-ky-su-da-tai-nhu-the/default.aspx) (29/05 12020)

4 Người mang trong mình giá trị cốt lõi Văn hóa Doanh nghiệp (../../9787/Nguoi-mang-trong-minh-giatri-cot-loi-Van-hoa-Doanh-nghiep/default.aspx) (26/05/2020)

4 VĂN HÓA DOANH NGHIẸP - YÉU TÓ VÀNG ĐÉ THÀNH CÔNG (.././/7494/NAN-HOA-DOANHNGHIEP-YEU-TO-VANG-DE-THANH-CONG/default.aspx) (26/12/2016)

\section{THÔNG BÁO (IANNOUNCE/DEFAULT.ASPX)}

20/01/2021 NQ HĐQT số 346/NQ-NĐHP về việc tổ chức ĐHĐCĐ thường niên 2021 (/notification/237/2206 /NQ-HDQT-so-346NQ-NDHP-ve-viec-to-chuc-DHDCD-thuong-nien-2021/default.aspx)

18/01/2021 Báo cáo tài chính Quý IV năm 2020 (trước kiểm toán) (/notification/237/2205/Bao-cao-tai-chinhQuy-IV-nam-2020-truoc-kiem-toan/default.aspx)

18/01/2021 công bố thông tin BCTC quý 4 năm 2020 (trước kiểm toán) (/notification/237/2204/cong-bothong-tin-BCTC-quy-4-nam-2020-truoc-kiem-toan/default.aspx)

27/11/2020 Công bố thông tin quyết định xử lý vi phạm về thuế (/notification/237/2203/Cong-bo-thong-tinquyet-dinh-xu-ly-vi-pham-ve-thue/default.aspx)

\section{LIÊN KÉT}

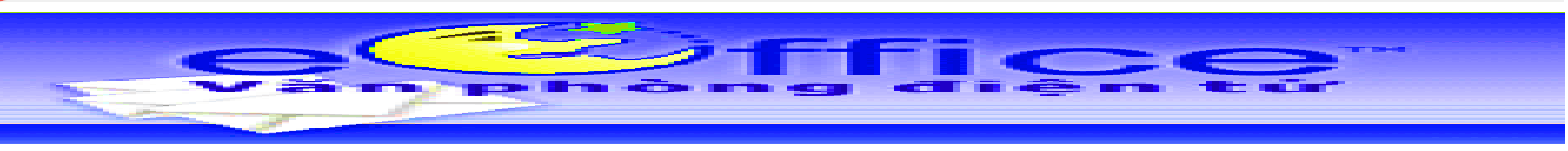

(http://113.160.101.102/congviec/) 


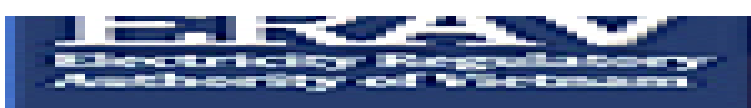

Cen

(http://www.erav.vn/)

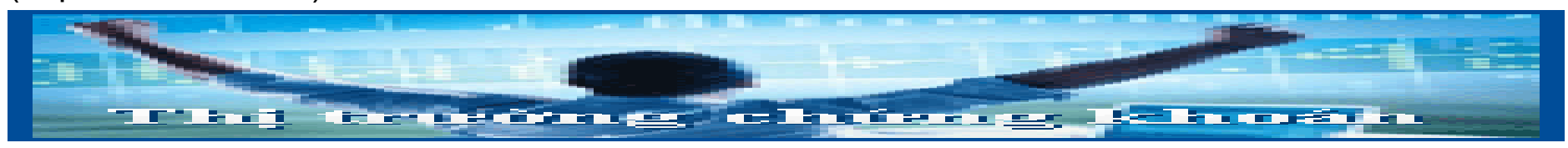

(http://banggia.vietstock.vn/)

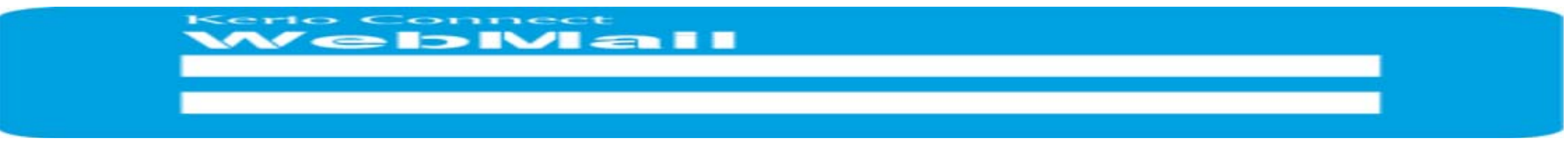

(http://123.26.251.170)
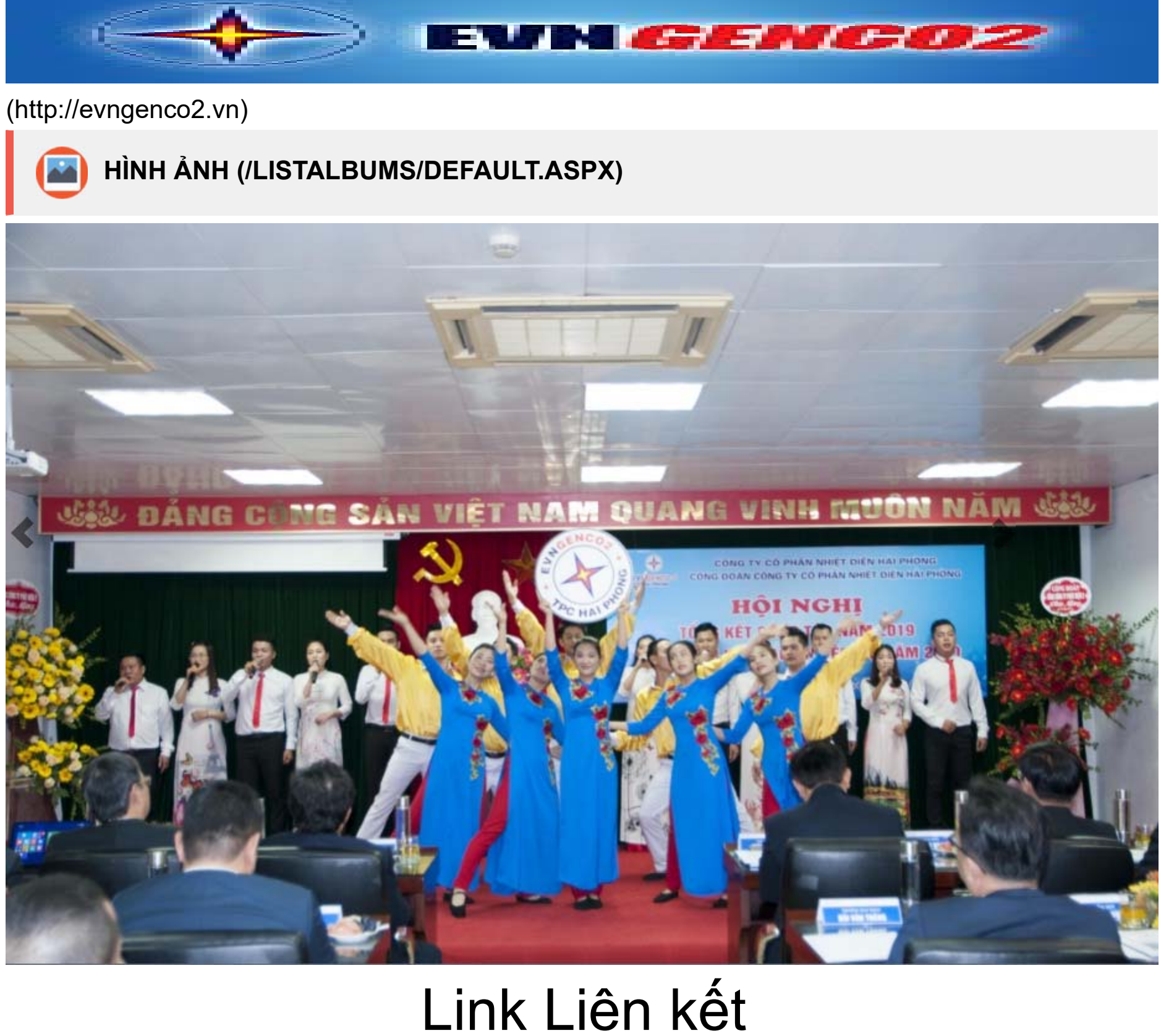

(A) TÂP DOÀN DIỆN LỰC VIỆT NAM 

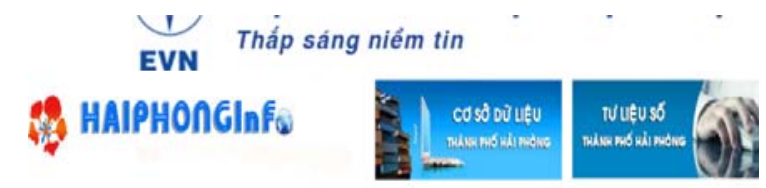

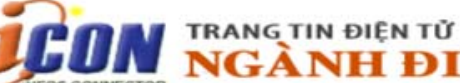

DOAN DAI BIEUU QUOC HOI VA HOI DONG NHAN DAN 2 T THANH PHÓ HÁI PHÒNG

* CổNG DỊCH Vụ CÔNG QUốc GIA

Kết nối, cung cấp thông tin và dịch vụ công mọi lúc, mọi nợi

\section{CÔNG TY CỎ PHẦN NHIẸT ĐIẸN HẢl PHÒNG}

Địa chỉ : Xã Tam Hưng - Huyện Thủy Nguyên - TP Hải Phòng Điện thoại: 02253775161 - Fax: 02253775162

Email: ndhpvn@ndhp.vn - Website: ndhp.com.vn 


\section{Tài liệu tham khảo:}

[1] EVN GENCO 2 CTCP Nhiệt Điện Hải Phòng. (2016). Văn hóa doanh nghiệp là gì?. Tin Văn hóa: http://www.ndhp.com.vn/newsg/5/7495/VAN-HOA-DOANH-NGHIEP-LA-GI/default.aspx

[2] Vương Quân Hoàng. (2007). Văn minh làm giàu \& Nguồn gốc của cải. Nxb Chính trị quốc gia, Hà Nội. 